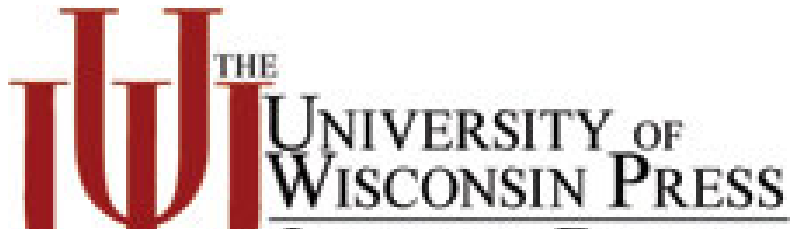 JouRNALS Division
}

The Board of Regents of the University of Wisconsin System

\author{
An Explicit Model of Intra-Metropolitan Mobility \\ Author(s): Eric A. Hanushek and John M. Quigley \\ Reviewed work(s): \\ Source: Land Economics, Vol. 54, No. 4 (Nov., 1978), pp. 411-429 \\ Published by: University of Wisconsin Press \\ Stable URL: http://www.jstor.org/stable/3146168 \\ Accessed: 14/01/2012 14:25
}

Your use of the JSTOR archive indicates your acceptance of the Terms \& Conditions of Use, available at http://www.jstor.org/page/info/about/policies/terms.jsp

JSTOR is a not-for-profit service that helps scholars, researchers, and students discover, use, and build upon a wide range of content in a trusted digital archive. We use information technology and tools to increase productivity and facilitate new forms of scholarship. For more information about JSTOR, please contact support@ jstor.org. 


\title{
An Explicit Model of Intra-Metropolitan Mobility
}

\author{
Eric A. Hanushek and John M. Quigley
}

\section{INTRODUCTION}

The study of local residential mobility is important from several perspectives. First, moving behavior provides insight into the dynamics of individual choice and the timing of adjustment for the single most important component of consumer expenditures. Additionally, household mobility has a direct impact upon the evolving spatial structure of urban areas and results in marginal changes in land use patterns and in the spatial distribution of sociodemographic groups. In fact, this latter implication of mobility has motivated a variety of studies by urban planners and transportation economists who have a practical interest in the aggregate outcomes of household mobility. Some of the outcomes of mobility are commonly observed and widely reported-the postwar decentralization of metropolitan areas and the process of neighborhood change and decline in central cities. Unfortunately, our understanding of the household mobility decision itself remains quite rudimentary.

The importance of household mobility is immediately apparent from aggregate statistics on moving behavior. Since annual statistics were first compiled in 1957 , almost 20 percent of all metropoli$\tan$ area residents have moved each year, and two-thirds of these moves have been within the same metropolitan area. ${ }^{1}$ Table 1 displays the distribution of
U.S. households in 1973 by length of tenure. Within SMSAs, over 40 percent of all households resided in their current dwelling for under 3.5 years; for renters, this figure was over 60 percent.

This analysis focuses on one aspect of residential mobility-the decision to change dwellings. As such, it represents a first step in understanding the underlying behavioral relationships and provides a direct test of several aspects of models of urban location and housing demand.

Most past analyses of residential mobility have not been related to underlying models of household behavior but instead have concentrated upon describing average moving probabilities for individuals with varying characteristics. For many policy purposes, such descriptive information is insufficient. This paper presents an explicit model of intrametropolitan mobility, a model in which moving behavior is derived from the demand for residential housing. Moving provides the only generally available means for households to adjust their housing consumption. This is especially important for renter households who

The authors are with the University of Rochester and Yale University, respectively. The research reported in this paper was originally sponsored by Abt Associates. Further support was provided through a grant from the Sloan Foundation. The authors are grateful to Robbe Burstine for research assistance.

1 See annual issues of Current Population Survey, Population Characteristics, Series P-20. 
TABLE 1

LENGTH OF TENURE IN YEARS AT CURRENT ADDRESS

(Percent of U.S. Households)

\begin{tabular}{cccccc}
\hline & $\begin{array}{c}\text { Less than } \\
1 \text { Year }\end{array}$ & $\begin{array}{c}1 \text { to } \\
3.5 \text { Years }\end{array}$ & $\begin{array}{c}3.5 \text { to } \\
8.5 \text { Years }\end{array}$ & $\begin{array}{c}8.5 \text { to } \\
13.5 \text { Years }\end{array}$ & $\begin{array}{c}13.5 \text { to } \\
23.5 \text { Years }\end{array}$ \\
\hline All Households & $19 \%$ & $21 \%$ & $23 \%$ & $12 \%$ & $14 \%$ \\
Outside SMSAs & 18 & 21 & 21 & 12 & 14 \\
Inside SMSAs & 20 & 21 & 23 & 13 & 14 \\
Central Cities & 20 & 21 & 24 & 12 & 13 \\
Owners & 8 & 15 & 23 & 15 & 21 \\
Renters & 32 & 27 & 24 & 9 & 6 \\
Suburbs & 19 & 22 & 23 & 12 & 15 \\
Owners & 10 & 19 & 25 & 15 & 20 \\
Renters & 41 & 29 & 19 & 6 & 3 \\
\hline
\end{tabular}

Source: U.S. Department of Commerce [1975].

have limited possibilities for changing the characteristics of the dwellings they occupy. Typically, there are substantial out-of-pocket costs of moving household possessions, important transactions costs in the form of security deposits, brokers' fees and the like, and significant search costs associated with residential mobility. These factors suggest that significant lags in adjustment are likely and that disequilibrium in housing consumption may be quite pervasive. The model focuses on the central nature of disequilibrium and adjustment lags in housing consumption.

Data gathered as part of the Housing Allowance Demand Experiment (HADE) provide an unusual opportunity to test the model. As part of the experiment, household re-interview data were collected at several points in time for the same households in two different housing markets (Pittsburgh and Phoenix). Thus, sufficient intertemporal data are available to analyze dynamic adjustment; more importantly, the same model can be replicated in different markets to indicate the generalizability of the model.
A focus on the adjustment behavior of individuals suggests some caution in the interpretation of aggregate analyses of urban housing markets, as commonly pursued by economists, with respect to local mobility and the potential for changes in urban structure. Aggregation across individuals (as described below) may understate the incentives for individual households to move and may thereby provide a misleading picture of the potential for changes in neighborhoods and urban spatial structure.

Understanding the behavioral structure of mobility decisions is essential both for the prediction of future changes in urban areas and for understanding the implications of many policies which affect urban areas. For example, demographic changes, such as later marriages and smaller families, have direct implications for housing demand. The prospect of demand-oriented housing subsidies highlights the policy significance of analyses of intra-urban mobility. In contrast with all previous housing subsidy programs, the HADE subsidy program puts minimal restrictions (in most cases no restrictions) on the 
housing type or location chosen by eligible households. Thus, in contrast to existing policies, an analysis of the effect of this experimental program requires an evaluation of its implications for intrametropolitan mobility. The analysis reported in this paper is confined to modelling the mobility behavior of households similar to those receiving experimental subsidies, but which are unaffected by the experiments themselves. Thus, it provides a benchmark for comparing household responses to experimental treatments.

Although this source of data provides a rich description of individual household characteristics and housing consumption at several points in time, the sample is restricted to renter households with relatively low incomes. This may suggest some caution in extrapolating the numerical results to the entire population, at least if one believes that the determinants of mobility are different, for some reason, for low-income households. Certainly, because of differences in transactions costs, the behavior of home owners would be at least quantitatively different from that observed for renters.

\section{CONCEPTUAL FRAMEWORK}

The bulk of existing empirical research on household moving behavior, undertaken mostly by sociologists and demographers, has been simply descriptive. Typically, these analyses relate the (cross sectionally observed) average moving propensities of households to measures of their current economic and demographic characteristics. While this research describes differential moving propensities of households with different socioeconomic characteristics, few specific hypotheses about household behavior have been rejected. ${ }^{2}$ In particular, correlations of current household characteristics with moving behavior neglect any notion that moving is a dynamic response to changed circumstances. ${ }^{3}$

A related line of inquiry, largely conducted by sociologists, has linked moving behavior and moving intentions to levels of "satisfaction" and the "stresses" of particular locations (usually based upon reported attitudes). This line of inquiry does link moving to dynamic factors, at least as they are reflected in attitude formation, but at the same time neglects most economic influences on household behavior.

Economists' analyses relate almost exclusively to the comparative statics of housing markets. With perfect information and no transactions costs, conventional residential location models (e.g., Alonso [1964] or Muth [1969]) derive, in a quite general way, the equilibrium household location and housing consumption, along with the overall surface of location rents and housing prices in a metropolitan area. Different initial conditions (such as different relative prices for housing services, different transportation costs, or different demand parameters) imply differences in the equilibrium solution of these models, and it is tempting to conclude that such comparative static analyses provide insight into both the aggregate dynamics of urban areas and the decisions of individuals. However, the adequacy of these models in describing the character of

\footnotetext{
2 See Quigley and Weinberg [1977] for a fairly detailed review and comparison of this literature.

3 This is the case unless changes in household characteristics are perfectly forecast by current characteristics.
} 
changes in housing markets depends crucially upon the nature of the adjustment process, that is, upon the magnitude of changes for individual households and the speed of adjustment in housing consumption. At the aggregate level, housing market disequilibrium may appear small since the overconsumption of some households will cancel the underconsumption of others; yet at the micro level, there may be large incentives to adjust.

The conceptual focus of the analysis of household mobility followed here concentrates upon demands for housing services by individuals. Moving is viewed simply as the means for adjusting housing consumption, and the incentive to move is related directly to changes in housing demand and disequilibrium in housing consumption. However, the observed relationship between actual moves and housing disequilibrium is complicated by significant transactions and search costs.

Consider a competitive housing market with no search or transactions costs in which households of particular demographic characteristics $(A)$ choose between housing $(H$, at price 1$)$ and other goods $(X$, at price $p)$. The demand function for housing indicates how housing consumption will change with income $(y)$; that is, equilibrium housing demand $\left(H^{d}\right)$ is a function of income and prices:

$H^{d}=g_{A}(y, p)$

In this world, with limited ability to transform the characteristics of a dwelling, any change in demand (say, from a change in income) would precipitate a move.

Adjustment and transactions costs make the moving decision more complex. With given transactions costs, a household will undertake to move only if its increase in utility, measured in dollars, exceeds these costs. In general, the welfare gain from adjusting housing consumption from $H_{o}^{d}$ to $H_{1}^{d}$ (in response to, say, an increase in income from $y_{o}$ to $y_{1}$ will be less than the difference in equilibrium expenditures $\left(H_{1}^{d}-H_{o}^{d}\right)$. This simply reflects substitution possibilities with other goods-if a household consumes less than its optimal amount of housing, it is partially compensated by consuming more of $X$. However, with reasonable utility functions and given transactions costs, the incentive to move remains a monotonic function of the change in equilibrium housing demand. ${ }^{4}$

The economics of search provides another reason why households' con-

\footnotetext{
${ }^{4}$ The utility change associated with different consumption levels for housing obviously depends upon the form of the underlying utility function. For example, if the utility function is Cobb-Douglas in terms of $H$ and $X$,

$U=H^{b}(y-H)^{1-b}$
}

then in equilibrium the household spends a fixed fraction of its income (by) on rent $(R=1 H)$. Consider a household initially consuming $H_{o}$ with income $y_{o}$ and with equilibrium housing consumption $H^{*}$. The amount of money $\left(y^{*}\right)$ required to make the household as well off with housing consumption $H_{o}$ as it would be at $H^{*}$ is: $y^{*}=\left(y_{o}-R^{*}\right)\left[\frac{R^{*}}{R_{g}}\right]^{b /(1-b)}+R_{o}$

and the income equivalent of moving $\left(y^{*}-y_{o}\right)$ is a monotonic function of the discrepancy between actual housing consumption and the equilibrium level of consumption. Without assuming some particular utility function, it is not possible to calculate the income equivalents of utility differences; it is nevertheless true for utility functions which are concave in $H$ and $X$ that this quantity will be an increasing function of the difference between current and equilibrium housing consumption.

Consideration of transactions costs is further complicated by questions of expectations and capitalization. Housing expenditures represent flows of services over some time period (as with monthly or annual expenditures). To compare utility differences with one-time transactions costs requires capitalization over the relevant decision horizon. Decision horizons and expectations are not directly observed, and little is known about them. In reality, the relevant decision horizon may well be endogenous and related to the magnitude of transactions costs. In particular, the 
sumption of housing may differ considerably from the equilibrium amount chosen in a frictionless world. For groups of "otherwise equivalent" dwelling units in a metropolitan area (e.g., identical dwelling units on the same isotransport-cost contour when viewed from an individual's workplace), there surely exists some distribution of rental prices; but, this price distribution is not known with certainty to the potential consumer. An exogenous shock (say, a change in family size or income) may change a household's equilibrium level of consumption. In response to this shock, the household will search for a dwelling unit if the expected gain from the activity exceeds the search costs. But the expected gain depends upon the household's currently perceived distribution of housing prices. An "unlucky" search (one that produces a unit whose price is "too high") may cause the rational household to cease searching-since the revised price distribution may simply reduce the expected gain from additional searching below the cost. ${ }^{5}$

This discussion implies that empirical analysis of even this simple model relating mobility solely to changes in housing demand is complicated. Moving decisions are a function not only of underlying housing demand but also of transactions costs, search costs, and the

decision horizon for home purchases is probably longer than that for rental contracts simply because of differences in transactions costs. Such endogeneity is not considered here, but the empirical work, based entirely on renters, eliminates this extreme difference. Expectations are clearly also related to the decision horizon. The subsequent analysis of renters in this paper assumes short decision horizons and myopic expectations. Specifically, households are presumed to make accurate one-year forecasts of their housing demands, and it is assumed that the realized economic and demographic conditions of the households at the end of the period reflect these expectations. distribution of housing prices. Little or no systematic data exist on these latter factors, although there are indications that they are likely to be large and important. ${ }^{6}$

Nevertheless, for given distributions of search and transactions costs, one would still expect a monotonic relationship between "mobility activity" and the gap between equilibrium demands and actual consumption. ${ }^{7}$ A simple specification of

5 Issues of decision horizons and capitalization enter also in optimum search, although, to our knowledge, they have not been explicitly considered. Most search models give simple stopping rules assuming fixed and known price distributions and one-time, permanent changes. However, particularly when consumption decisions are made infrequently-as with housing assumptions of known distributions may be very unrealistic. When the price distributions are unknown, models of optimal search are much less helpful (see Rothschild [1974]).

6 There are at least two monetary components of relocation costs: the costs of moving household possessions, and the out-of-pocket costs particular to each type of tenure. For homeowners, these latter costs include brokers' fees, the costs of title search, and other closing costs; these are estimated to be $10-20$ percent of annual expenditures (see de Leeuw and Ekanem [1971]; Shelton [1968]). For renters, these costs include foregone interest (or liquidity constraints) resulting from security and lease deposits and the like.

More importantly for renters, however, these transactions costs must include any rent discounts attributable to longer-term occupancy. Long-term occupancy by tenants can result in significant cost savings to landlords-not only a reduction in painting and redecorating expenditures, but also a reduction in the expected vacancy rate of rental units. In a competitive market, even with perfect information on the part of landlords, we expect some or all of these savings to be passed along to tenants.

There is some empirical evidence on the relative magnitude of the reductions in gross rent attributable to long-term occupancy. See Kain and Quigley [1975] and Schafer [forthcoming]. See also note 13.

7 In the empirical analysis which follows, we measure mobility activity in two ways: by means of a dichotomous variable reflecting the decision to move or not to move; and by means of a trichotomous variable distinguishing those who search and move, those who search only, and those who take no action. In the discussion we often refer simply to moving or mobility, but these should be read as also considering search behavior. 
the relationship is obtained by assuming that behavioral responses to disequilibrium by households are the same, regardless of whether households are currently underconsuming or overconsuming housing relative to their equilibrium demands. In this case, disequilibrium is a function of the absolute value of the discrepancy between desired and actual consumption, and, given transactions and search costs $(c)$, mobility $\left(M_{t}\right.$ during the period $t$ to $t+1$ can be represented as: ${ }^{8}$

$M_{t}=f\left[\left|H_{t+1}^{d}-H_{t}\right| ; c\right]$

This specification is quite rigid, however, and a variety of alternative specifications are plausible.

Past mobility studies, particularly by sociologists, often conclude that mobility is a discontinuous behavioral reaction, resulting from some immediate stimulus rather than from a continuous calculation of levels of "dissatisfaction." In this context, we can identify the immediate stimulus by noting that:

$$
H_{t+1}^{d}-H_{t}=\left[H_{t}^{d}-H_{t}\right]+\left[H_{t+1}^{d}-H_{t}^{d}\right]
$$

In words, the amount of disequilibrium can be decomposed into an initial disequilibrium and the change in the desired consumption over the period. A differential response to immediate and ongoing stimuli can be tested by relying on this decomposition of the disequilibrium "gap" in housing consumption. ${ }^{9}$ This extension can be represented as:

$M_{t}=f\left[\left|H_{t}^{d}-H_{t}\right|,\left|H_{t+1}^{d}-H_{t}^{d}\right| ; c\right]$

These simple models imply a symmetrical response to disequilibrium situations. However, there is some reason to expect a "rachet" effect in housing consumption. In particular, households are likely to be more sensitive to "under- consuming" as opposed to "overconsuming" housing. If this is true, then positive differences between desired and actual consumption will have a larger impact on mobility activity than negative differences. This type of behavior may be tested by dividing the disequilibrium term(s) according to algebraic sign.

\section{EMPIRICAL ANALYSIS}

Data on households and housing consumption are available in two metropolitan housing markets-Pittsburgh and Phoenix - at three points in time: an initial "baseline" interview $(t=0)$; after approximately 12 months $(t=1)$; and after an additional 12 months $(t=2) .{ }^{10}$ Yet, even under the restrictive assumptions introduced so far, the series of models implied by equations [2] and [4] cannot be estimated directly, since they include equilibrium housing demand which is not directly observed. Desired, or equilibrium, housing demand is calculated for each household in each period $\left(H_{o}^{d}, H_{1}^{d}\right.$, and $\left.H_{2}^{d}\right)$ from estimated housing demand models and observed household characteristics. The demand functions, reported in the Ap-

\footnotetext{
8 This illustrates the differences between analyses of dynamic household behavior at the individual level and aggregate analyses of changes in housing markets: Disequilibrium cannot be aggregated simply across individuals.

${ }^{9}$ As noted, the economics of search when the distribution of prices is unknown also suggests that changes in desired consumption will have a larger impact on mobility activity than built-up disequilibrium in housing consumption.

10 All moving analysis reported here is based upon the control group from the Housing Allowance Demand Experiment. These households receive no subsidy payments and, therefore, can be treated simply as sample observations reflecting normal housing market observations, at least for lower-income renters.
} 
pendix, rely on previous work by us (see Hanushek and Quigley [1978]) and are similar in specification to those reported by other researchers using samples of individual households. Their interpretation as equilibrium demand functions is based upon two assumptions: that the demands observed by recent movers in the housing market represent their utility-maximizing or equilibrium consumption levels; and that the housing price surfaces in the two metropolitan areas analyzed exhibit no discernible price gradient from a central workplace. ${ }^{11}$

Equilibrium housing demand is estimated for recent mover households in each housing market from linear regressions of contract rent on income, assets, and sociodemographic characteristics along with standardizations for contractual terms. This procedure, while yielding unbiased estimates of the systematic differences in equilibrium demand based upon observed characteristics, may introduce systematic errors if there exist household-specific, but unmeasured, influences on desired consumption. ${ }^{12}$ The implications of this for interpreting the results are discussed below.

Actual housing expenditures (monthly rent) of each household are transformed to a measure of the quantity of housing services actually consumed $\left(\mathrm{H}_{o}, \mathrm{H}_{1}, \mathrm{H}_{2}\right)$ by standardizing for contractual terms (i.e., the inclusion of utilities in rental contracts) and for length of tenure. ${ }^{13}$ These data, taken together, allow estimation of the extent of housing disequilibrium.

The appropriate functional form is related to the shape of the utility function and the distribution of search and transactions costs, and in general we would not expect a linear relationship between moving and disequilibrium. For analytical purposes, we first define disequilibri-
11 In estimating hedonic housing price models in these two metropolitan areas, Merrill tests for equality of coefficients between central city and suburbs. For Pittsburgh, it is not possible to reject the hypothesis of coefficient equality at the 5 percent level; for Phoenix, the hypothesis can be rejected, although the models are quite similar and the standard error of estimate only changes slightly with stratification. Independent analysis of the Pittsburgh area conducted for the NBER Urban Simulation Model by Gregory Ingram provided no evidence of a housing price gradient [reported in private correspondence].

These models assume that utility is defined over an index of the quantity of housing consumed. In reality, "housing" is a heterogeneous good whose quantity varies in several dimensions. The empirical analysis employs the convenient (and widely used) assumption that housing expenditures are a single-valued measure of the housing services consumed-including the structural and qualitative characteristics of dwelling units and locations, along with the capitalized value of neighborhood amenities and public services. By measuring housing services through a price-weighted index of housing characteristics, it is also implicitly assumed that the supply elasticities for different characteristics are the same. To the extent that households have identifiable demands for particular characteristics of the housing bundle and to the extent that these are differentially supplied, measuring disequilibrium by a single index is an oversimplification. The empirical analysis below suggests that aggregation across housing attributes is acceptable.

12 As explained in the Appendix, the demand estimation was conducted for a different, but partially overlapping, sample of households using baseline data. Had the samples been the same, it would have been possible to incorporate information about individual household deviations from "expected equilibrium demand." See below.

13 In a competitive market, the contract rents (standardized for the provision of utilities by the landlord or tenant) paid by individuals with a standardized duration of occupancy are an unambiguous measure of the quantity of housing services actually consumed.

The portion of transactions costs (see note 6) arising from tenure discounts is explicitly included. Tenure discounts were estimated in the Pittsburgh and Phoenix housing markets in an analysis of hedonic prices conducted by Merrill [1976]. In that study, log rent is regressed upon a series of structure and quality measures of individual dwelling units and the length of tenure of the occupying household. The regression coefficients, based on a sample of 1,509 dwelling units in Pittsburgh and 1,601 dwelling units in Phoenix, imply significant price discounts for long-term residents. In Pittsburgh, the results indicate discounts of 2 percent for households with 1-5 years of occupancy, increasing to 10 percent for households with more than 10 years occupancy. In Phoenix, the tenure discounts range from 
um in percentage deviations from initial equilibrium demand and disaggregate it as follows: ${ }^{14}$

$$
\begin{aligned}
D_{\text {TOT }}= & \text { total disequilibrium between } t \text { and } t+1 \\
= & \left(H_{t+1}^{d}-H_{t}\right) / H_{t}^{d} ; \\
D_{O}= & \text { initial disequilibrium } \\
= & \left(H_{t}^{d}-H_{t}\right) / H_{t}^{d} ; \\
D_{E}= & \text { change in equilibrium between } t \text { and } \\
& t+1 \\
= & \left(H_{t+1}^{d}-H_{t}^{d}\right) / H_{t}^{d} .
\end{aligned}
$$

Table 2 presents summary information on the housing disequilibrium obsęrved in the two samples. It illustrates quite vividly how the magnitude of moving incentives for individual households is affected by aggregation. The aggregate level of disequilibrium in housing consumption (averaging over households) is estimated to be 6-9 percent in Phoenix and $10-12$ percent in Pittsburgh. However, the behavioral model indicates that average absolute deviations between actual and equilibrium housing consumption is a more accurate measure of moving incentives. As shown in Table 2, in the aggregate this amounts to some 20 percent for both time periods and both housing markets. The pattern of disequilibrium is similar across the two cities. A majority of households in each sample tend to be underconsuming housing (e.g., 58 percent of Phoenix households and 70 percent of Pittsburgh households during the first year). Further, the average amount of underconsumption is almost twice the average amount of overconsumption. The magnitude of initial dis-

4.4 percent for households with $1-5$ years of occupancy to 19 percent for households with more than 10 years of occupancy. These coefficients permit the housing consumption of each household to be estimated from monthly housing expenditures. Consumption is normalized to new occupants (consistent with the equilibrium demands discussed in the Appendix). equilibrium $\left(D_{O}\right)$ is systematically higher than the change in equilibrium $\left(D_{E}\right)$ over the period; this skewness in deviations of observed from equilibrium consumption suggests significant lags in adjustment. ${ }^{15}$

Direct information about transactions costs (other than tenure discounts) and search costs-the final elements in the moving model-is unavailable. For empirical application, we assume that the distribution of these costs is normal and is independent of the estimated disequilibrium values. This implies that probit estimation provides the appropriate nonlinear functional form. ${ }^{16}$

\footnotetext{
${ }^{14}$ Similar models were also estimated using simple differences between desired and actual consumption (e.g., $D_{T O T}^{*}=H_{t+1}^{d}-H_{t}$ ). These latter models consistently yielded poorer results in terms of both $\chi^{2}$ tests for overall significance and significance tests on individual coefficients.

15 The changes in equilibrium $\left(D_{E}\right)$ are, on average, in the direction of increasing equilibrium demand and amount to between 0.5 and 2.5 percent annual increases. This reflects increases in income, assets, and family size over time and the life cycle. (The sampling procedure follows a fixed set of households through time; therefore, incomes and demographic composition will follow specific life cycle patterns which differ systematically from changes in population average characteristics). The total disequilibrium indicates that adjustments are slow and disequilibrium tends to accumulate over a period of time. An alternative explanation to the observed average underconsumption might be that individual expectations are systematically bad or myopic. However, the relative magnitude of $D_{T O T}$ to $D_{E}$ suggests adjustment lags rather than faulty expectations.

16 Binary choice models (move or no move) were also estimated assuming the logistic functional form, and the results were indistinguishable. Probit estimates are reported to facilitate comparison with the trichotomous choice models (move, search without move, or no move) presented subsequently. Maximum likelihood techniques are used in the estimation, and, assuming the
} errors are normally distributed,

probit $[X]=\frac{1}{\sqrt{2} \pi} \int_{-x}^{x} e^{-\frac{u^{2}}{2}} d u$

See Hanushek and Jackson [1977, chap. 7]. The binary choice models imply that the combination of transaction and search costs follow a common normal distribution while the trichotomous models allow different (normal) distributions for the two costs. The magnitude of search and transactions costs are assumed independent of the level of disequilibrium. 


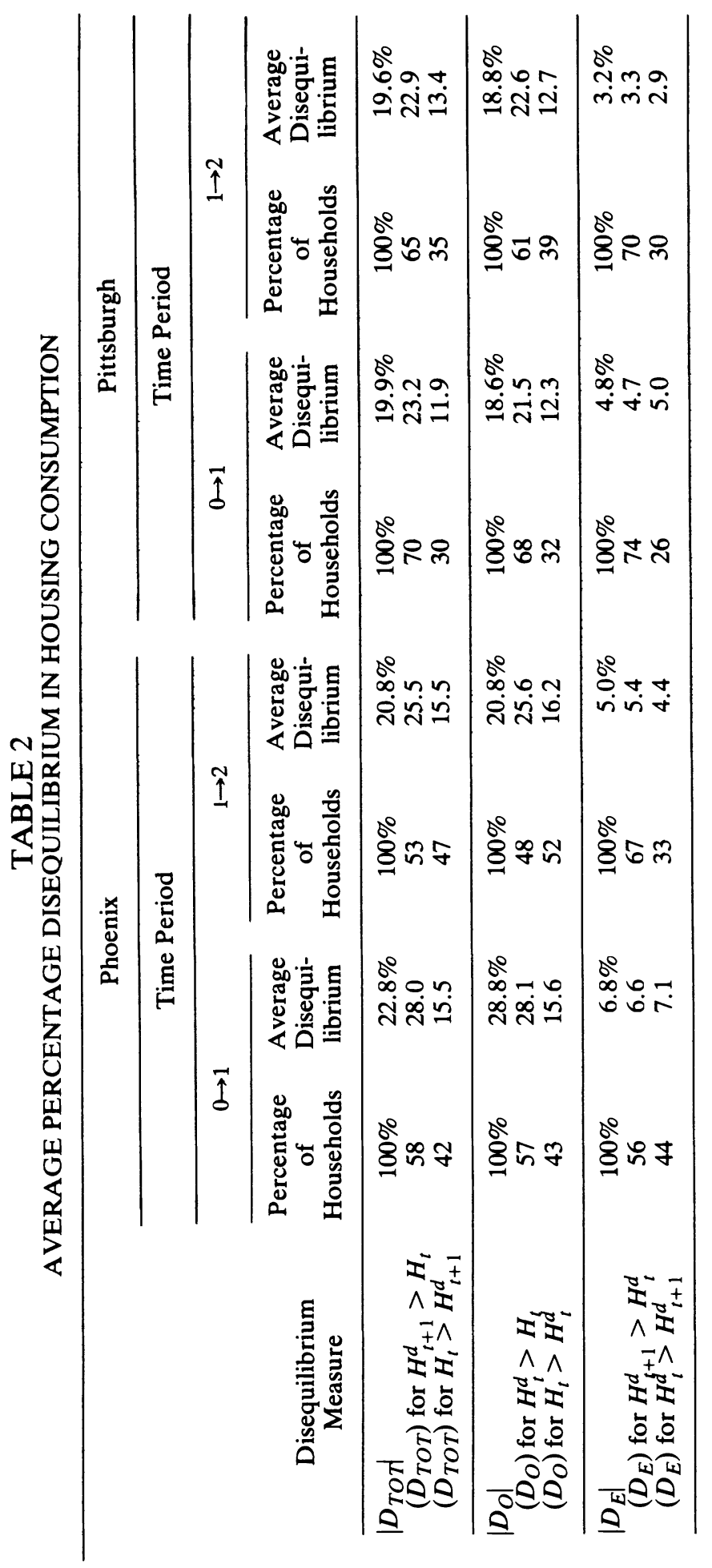


Letting $\rho_{t, t+1}$ be the underlying moving probabilities during the interval $t$ to $t+1$, the specific models are:

$$
\begin{aligned}
\rho_{t, t+1}= & \text { probit }\left[\mu_{1}+\alpha\left|D_{T O T}\right|+\eta_{1}\right] \\
\rho_{t, t+1}= & \text { probit }\left[\mu_{2}+\beta\left|D_{O}\right|+\gamma\left|D_{E}\right|+\eta_{2}\right] \\
\rho_{t, t+1}= & \text { probit }\left[\mu_{3}+\alpha^{+} \delta_{1}\left|D_{T O T}\right|\right. \\
& \left.+\alpha^{-} \delta_{2} \mid D_{T O T}+\eta_{3}\right]
\end{aligned}
$$

and,

$$
\begin{aligned}
\rho_{t, t+1}= & \text { probit }\left[\mu_{4}+\beta^{+} \delta_{3}\left|D_{O}\right|+\beta^{-} \delta_{4}\left|D_{O}\right|\right. \\
& \left.+\gamma^{+} \delta_{5}\left|D_{E}\right|+\gamma^{-} \delta_{6}\left|D_{E}\right|+\eta_{4}\right]
\end{aligned}
$$

where $\delta_{i}, i=1, \ldots, 6$, are binary variables equal to zero except:

$$
\begin{aligned}
& \delta_{1}=1 \text { if } H_{t+1}^{d}>H_{t} \\
& \delta_{2}=1 \text { if } H_{t+1}^{d}<H_{t} \\
& \delta_{3}=1 \text { if } H_{t}^{d}>H_{t} \\
& \delta_{4}=1 \text { if } H_{t}^{d}<H_{t} \\
& \delta_{5}=1 \text { if } H_{t+1}^{d}>H_{t}^{d} \\
& \delta_{6}=1 \text { if } H_{t+1}^{d}<H_{t}^{d}
\end{aligned}
$$

The $\eta$ 's, $\alpha$ 's, $\beta$ 's and $\gamma$ 's are parameters to be estimated, and the $\mu$ 's are stochastic terms, assumed to be standard normal.

\section{Binary Choice: The Move Decision}

Table 3 presents maximum likelihood estimates of the basic models, equations [5] and [6], for each cohort of households. The results provide only weak support for the simplest model, equation [5], which does not distinguish between the two components of household disequilibrium. In only one of the four equations is the estimated adjustment coefficient significantly different from zero.

The results are much stronger, however, for the estimates of equation [6], which distinguishes between initial disequilibrium and its change during the one-year period. The estimates of $\gamma-$ the responsiveness of household mobility to changes in equilibrium housing demand -is highly significant for both replications of the model of Phoenix. The asymptotic $t$-ratios are only slightly lower for the replications for Pittsburgh households.

Table 4 presents the estimated coefficients of the disaggregated models which distinguish disequilibrium by its algebraic sign, i.e., distinguishing between those households overconsuming and underconsuming housing, relative to equilibrium demand. Again, the results provide little support for the model which does not distinguish between the initial level of disequilibrium and its change during the one-year interval. However, the results for the fully disaggregated model, equation [8], strongly support the underlying theory, suggesting that households whose equilibrium level of housing demand increases are far more likely to move; the estimates of $\gamma^{+}$ are highly significant in all cases. The other estimated coefficients are generally insignificant, although they have the correct sign in ten of the twelve cases.

The estimated changes in moving propensity due to changes in initial disequilibrium and changes in desired housing are presented in Table 5. When equation [6] is evaluated at the means, a 10 percent increase in desired housing consumption increases the probability of moving by 9 to 15 percentage points. Interestingly, while the average moving propensity in Phoenix is roughly double that in Pittsburgh, the responsiveness to changed desired housing is approximately the same.

Despite the crudeness of the demand estimation and the stringency of the moving models, the adjustment models work rather well. As noted in the 
TABLE 3

A. BASIC MOVE MODELS

$\rho_{t, t+1}=$ probit $\left[\mu_{1}+\alpha \mid D_{T o t}+\eta_{1}\right]$

\begin{tabular}{lccccc}
\hline & \multicolumn{2}{c}{ Phoenix } & & \multicolumn{2}{c}{ Pittsburgh } \\
\cline { 2 - 3 } \cline { 5 - 6 } & $0 \rightarrow 1$ & $1 \rightarrow 2$ & & $0 \rightarrow 1$ & $1 \rightarrow 2$ \\
\hline$\alpha$ & 0.8978 & -0.7861 & & 0.2365 & 0.3258 \\
$\eta_{1}$ & $(2.044)$ & $(1.531)$ & & $(0.381)$ & $(0.558)$ \\
& -0.3481 & -0.2293 & & -0.8104 & -0.9719 \\
$\chi^{2}$ & $(2.746)$ & $(1.760)$ & & $(5.306)$ & $(6.503)$ \\
$\chi^{2}(.10,1 \mathrm{df})=2.706$ & 4.242 & 2.240 & & 0.145 & 0.309 \\
$\chi^{2}(.20,1 \mathrm{df})=1.642$ & & & & \\
\hline
\end{tabular}

B. EXPANDED MOVE MODELS

$\rho_{t, t+1}=$ probit $\left[\mu_{2}+\beta\left|D_{O}\right|+\gamma\left|D_{E}\right|+\eta_{2}\right]$

\begin{tabular}{lccccc}
\hline & \multicolumn{2}{c}{ Phoenix } & & \multicolumn{2}{c}{ Pittsburgh } \\
\cline { 2 - 3 } \cline { 5 - 6 } & $0 \rightarrow 1$ & $1 \rightarrow 2$ & & $0 \rightarrow 1$ & $1 \rightarrow 2$ \\
\hline & 0.8846 & -0.4215 & & 0.3376 & 0.1756 \\
& $(1.827)$ & $(0.788)$ & & $(0.512)$ & $(0.287)$ \\
$\eta_{2}$ & 2.3427 & 3.8093 & & 3.4146 & 4.6465 \\
& $(2.017)$ & $(2.417)$ & & $(1.918)$ & $(1.863)$ \\
$\chi^{2}$ & -0.5005 & -0.4972 & & -0.9980 & -1.0938 \\
$\chi^{2}(.10,2$ df $)=4.605$ & $(3.246)$ & $(3.005)$ & & $(5.323)$ & $(6.301)$ \\
$\chi^{2}(.20,2 \mathrm{df})=3.219$ & 7.840 & 7.604 & & 3.647 & 3.555 \\
\hline
\end{tabular}

Note: Asymptotic $t$-ratios in parentheses.

Appendix, the demand models do not include a very complete description of individuals and leave considerable variation in housing demand unexplained. In addition, the estimation of disequilibrium constrains the effects of changes in demographic and economic factors to follow the demand relationship and, thus, tests only the effect of housing demand upon mobility.

Consideration of errors in estimation of equilibrium demand helps reconcile the results of the basic and expanded models (Table 3 ) and provides a somewhat stronger interpretation of the re- sults. A more realistic specification of the equilibrium demand relationship might be:

$H_{i t}^{d}=X_{i t} \beta+\zeta_{i}+\epsilon_{i t}$

where $X_{i t} \beta$ is the systematic portion of demand, estimated in the demand models, $\zeta_{i}$ is a household-specific error term (reflecting differences in tastes and unmeasured factors), and $\epsilon_{i t}$ is a stochastic term independent of $X_{i t}$ and $\zeta_{i}$. In this standard error components framework which incorporates individual heterogeneity, cross sectional estimates of $\beta$ using ordinary least squares will be 
TABLE 4

A. DISAGGREGATED MOVE MODELS

$\rho_{t, t+1}=$ probit $\left[\mu_{3}+\alpha^{+} \delta_{1}\left|D_{T O T}\right|+\alpha^{-} \delta_{2}\left|D_{T O T}\right|+\eta_{3}\right]$

\begin{tabular}{lccccc}
\hline & \multicolumn{2}{c}{ Phoenix } & & \multicolumn{2}{c}{ Pittsburgh } \\
\cline { 2 - 3 } \cline { 5 - 6 } & $0 \rightarrow 1$ & $1 \rightarrow 2$ & & $0 \rightarrow 1$ & $1 \rightarrow 2$ \\
\hline$\alpha^{+}$ & 0.9136 & -0.7906 & & 0.2260 & 0.3622 \\
& $(2.070)$ & $(1.536)$ & $(0.364)$ & $(0.616)$ \\
$\alpha^{-}$ & 1.2114 & -0.6615 & & -0.0630 & 1.4067 \\
& $(1.240)$ & $(0.720)$ & $(0.043)$ & $(1.070)$ \\
$\eta_{3}$ & -0.3710 & -0.2379 & & -0.7983 & -1.0303 \\
& $(2.614)$ & $(1.692)$ & & $(4.942)$ & $(6.296)$ \\
$\chi^{2}$ & 4.371 & 2.425 & & 0.198 & 1.137 \\
$\chi^{2}(.10,2 \mathrm{df})=4.605$ & & & & \\
$\chi^{2}(.20,2 \mathrm{df})=3.219$ & & & & \\
\hline
\end{tabular}

B. FULLY DISAGGREGATED MOVE MODELS

$\rho_{t, t+1}=$ probit $\left[\mu_{4}+\beta^{+} \delta_{3}\left|D_{O}\right|+\beta^{-} \delta_{4}\left|D_{O}\right|+\gamma^{+} \delta_{5}\left|D_{E}\right|+\gamma^{-} \delta_{6}\left|D_{E}\right|+\eta_{4}\right]$

\begin{tabular}{lccccc}
\hline & \multicolumn{2}{c}{ Phoenix } & & \multicolumn{2}{c}{ Pittsburgh } \\
\cline { 2 - 3 } \cline { 5 - 5 } & $0 \rightarrow 1$ & $1 \rightarrow 2$ & & $0 \rightarrow 1$ & $1 \rightarrow 2$ \\
\hline$\beta^{+}$ & 0.9169 & -0.4460 & & 0.5368 & 0.2869 \\
$\beta^{-}$ & $(1.872)$ & $(0.821)$ & & $(0.795)$ & $(0.463)$ \\
& 1.3094 & 0.5919 & & 1.5254 & 1.8278 \\
$\gamma^{+}$ & $(1.244)$ & $(0.639)$ & & $(1.093)$ & $(1.387)$ \\
& 2.9057 & 4.2954 & & 5.5927 & 5.9866 \\
$\gamma^{-}$ & $(1.901)$ & $(2.563)$ & & $(2.667)$ & $(2.223)$ \\
& 2.0621 & 3.0068 & & 0.0612 & 0.5621 \\
$\eta_{4}$ & $(1.520)$ & $(1.048)$ & & $(0.021)$ & $(0.114)$ \\
& -0.5463 & -0.5856 & & -1.1146 & -1.1935 \\
$\chi^{2}$ & $(3.115)$ & $(3.188)$ & & $(5.389)$ & $(6.214)$ \\
$\chi^{2}(.10,4$ df $)=7.779$ & 8.358 & 9.900 & & 8.355 & 6.582 \\
$\chi^{2}(.20,4$ df $)=5.989$ & & & & \\
\hline
\end{tabular}

Note: Asymptotic $t$-ratios in parentheses.

unbiased if $\zeta_{l}$ is independent of $X_{t r}$ However, the estimate of disequilibrium obtained $\left(X_{i t+1} \hat{\beta}-H_{i t}\right)$ could contain considerable error (i.e., $\zeta_{i}$ ) for each household. The effect will be to bias the estimated effect of $D_{T O T}$ on moving toward zero (by a standard errors in variables argument). However, if $\zeta_{i}$ is fixed for an individual household in the short run, the change in equilibrium $\left(D_{E}\right)$ will be accurately measured, since the $\zeta_{i}$ 's cancel. Thus, the estimated effects of changes in equilibrium housing demand will be unbiased, and the expanded model should give a better test of the housing demand model and a better estimate of the adjustment lags. ${ }^{17}$

17 The undeslying survey data also contain direct attitudinal questions about satisfaction with housingcoded on a four-point scale from "very dissatisfied" to "very satisfied". These data were used to form instruments for the disequilibrium estimates in a twostage estimation. However, this cstimation proved very unsuccessful. 
TABLE 5

CHANGE IN MOVING PROBABILITIES FROM 10 PERCENT

INCREASE IN DISEQUILIBRIUM ${ }^{\mathrm{a}}$

(Evaluated at Means)

\begin{tabular}{lccccc}
\hline & \multicolumn{2}{c}{ Phoenix } & & \multicolumn{2}{c}{ Pittsburgh } \\
\cline { 2 - 3 } \cline { 5 - 6 } & $0 \rightarrow 1$ & $1 \rightarrow 2$ & & $0 \rightarrow 1$ & $1 \rightarrow 2$ \\
\hline Change in disequilibrium & & & & \\
$D_{O}=.1$ & .035 & $-.017^{\mathrm{b}}$ & & $.007^{\mathrm{b}}$ & $.003^{\mathrm{b}}$ \\
$D_{E}=.1$ & .093 & .146 & .112 & .144 \\
Mean probability of move & .443 & .349 & & .223 & .182 \\
\hline
\end{tabular}

a Probabilities estimated from models in Table 3B.

b Asymptotic $t$-test for coefficient in probit models not significantly different from zero at .05 level.

\section{Trichotomous Choice: Move and Search Decisions}

The results presented in Tables 3 and 4 provide general support for the economic model of intra-urban mobility. The results suggest strongly that changes in equilibrium demand, particularly increases in demand, are associated with household decisions to move. These results are quite consistent for two successive one-year intervals for households in two differing metropolitan areas. These models assume there are two observable responses to the stimulus provided by housing market disequilibrium-moving and non-moving.

In fact, however, the behavior of real households is more complex. Before households can move in response to disequilibrium in housing demand, they generally must invest some resources in searching for an alternative dwelling unit. For households with a given prior price distribution, the conceptual discussion suggests that larger disequilibrium will increase the propensity both to search and to move. Data about search behavior of households could therefore improve our understanding of adjustment to housing disequilibrium.
This section uses additional information to analyze the trichotomous behavior of: (a) moving; (b) searching but not moving; and (c) neither searching nor moving. ${ }^{18}$ Since this behavior is ordered in terms of intensity of response to disequilibrium, it is possible to use a generalization of the probit model to estimate more general models of adjustment (see Hanushek and Jackson [1977]). Incorporation of information about search behavior involves estimation of an additional parameter; this represents a parallel shift in the probit plane, distinguishing the third category (searching) from the other two. It should be noted that this specification assumes that the influence of the level of disequilibrium upon searching and upon moving behavior can be represented by a common parameter (see Aitchison and Silvey [1957]).

Table 6 presents the results of the probit models reestimated for the trichotomous case and extending the

\footnotetext{
18 Moving behavior is, of course, observed directly. Searching behavior is inferred from the answer to: "During [this time interval] have you or anyone in your household looked for or tried to find a new house or apartment?"
} 
TABLE 6

A. BASIC SEARCH/MOVE MODELS

$M_{t, t+1}=$ probit $\left[\mu_{1}+\alpha\left|D_{T O T}\right|+\eta_{1}+\eta_{1}^{*}\right]$

\begin{tabular}{|c|c|c|c|c|}
\hline & \multicolumn{2}{|c|}{ Phoenix } & \multicolumn{2}{|c|}{ Pittsburgh } \\
\hline & $0 \rightarrow 1$ & $1 \rightarrow 2$ & $0 \rightarrow 1$ & $1 \rightarrow 2$ \\
\hline $\begin{array}{l}\alpha \\
\eta_{1} \\
\eta_{1}^{*}\end{array}$ & $\begin{array}{c}0.6744 \\
(1.61) \\
-0.2035 \\
(2.31) \\
-0.3700 \\
(6.60)\end{array}$ & $\begin{array}{c}-0.9451 \\
(2.05) \\
-0.1620 \\
(1.31) \\
-0.4352 \\
(7.09)\end{array}$ & $\begin{array}{c}0.0820 \\
(0.15) \\
-0.7704 \\
(5.55) \\
-0.6301 \\
(8.23)\end{array}$ & $\begin{array}{c}0.1608 \\
(0.32) \\
-0.5894 \\
(7.53) \\
-0.5894 \\
(6.73)\end{array}$ \\
\hline $\begin{array}{l}\chi^{2} \\
\chi^{2}(.10,1 \mathrm{df})=2.71 \\
\chi^{2}(.20,1 \mathrm{df})=1.64\end{array}$ & 2.62 & 4.99 & .02 & .10 \\
\hline
\end{tabular}

B. EXPANDED SEARCH/MOVE MODELS

$M_{t, t+1}=$ probit $\left[\mu_{2}+\beta\left|D_{O}\right|+\gamma\left|D_{E}\right|+\eta_{2}+\eta_{2}^{*}\right]$

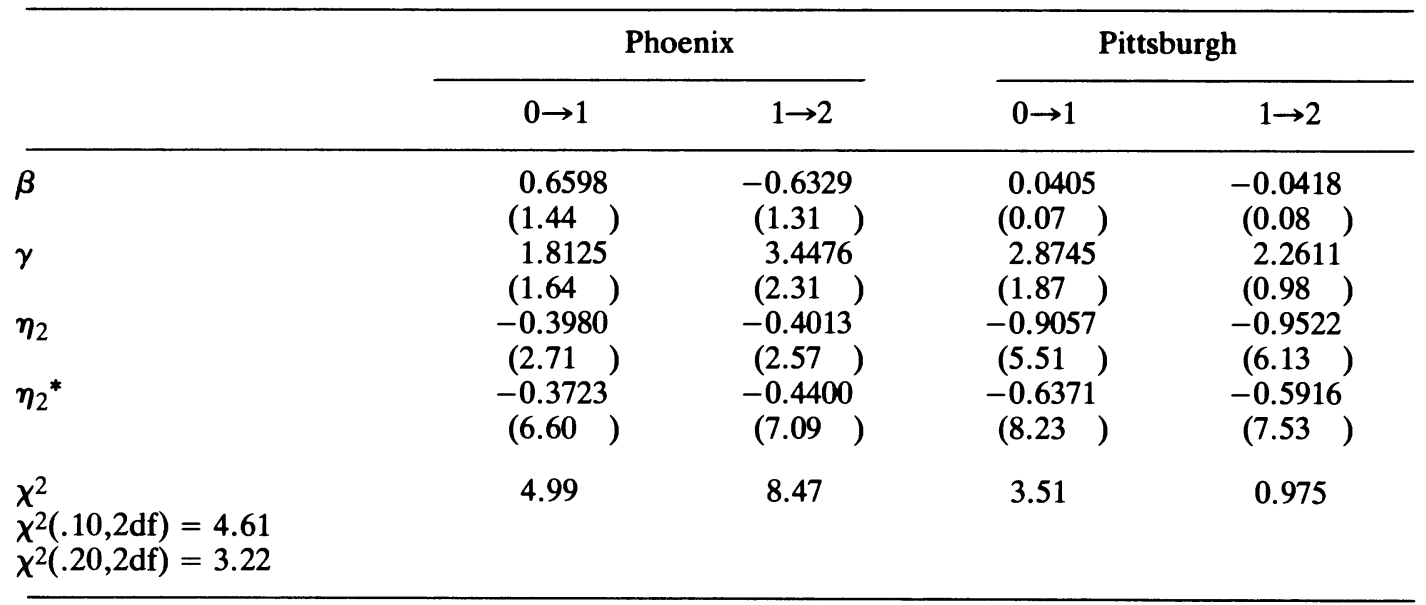

Note: $M_{t, t+1}=(0,0)$ if no search and no move; $=(1,0)$ if search but no move; and $=(1,1)$ if search and move. $\eta_{l}{ }^{*}$ represents the shift in the probit plane for search without move. Asymptotic $t$-ratios in parentheses.

models reported in Table 3 . The results are qualitatively similar to the binary decision models: There appears to be little empirical support for the simplest model, but the expanded model indicates the importance of changes in equilibrium housing consumption in motivating both search behavior and subsequent residential mobility. ${ }^{19}$
The estimated changes in moving and searching propensities due to changes in initial disequilibrium and changes in desired housing are presented in Table 7. At the means, a 10 percent change in

\footnotetext{
19 Reestimates (not shown) of the more disaggregated models presented in Table 4 for the trichotomous case yielded results similar to those reported above.
} 
TABLE 7

CHANGE IN MOVING AND SEARCH PROBABILITIES FROM 10 PERCENT INCREASE IN DISEQUILIBRIUM ${ }^{\mathrm{a}}$

(Evaluated at Means)

\begin{tabular}{|c|c|c|c|c|}
\hline & \multicolumn{2}{|c|}{ Phoenix } & \multicolumn{2}{|c|}{ Pittsburgh } \\
\hline & $0 \rightarrow 1$ & $1 \rightarrow 2$ & $0 \rightarrow 1$ & $1 \rightarrow 2$ \\
\hline & \multicolumn{4}{|c|}{ Net Change in Probability of Move } \\
\hline \multirow[t]{2}{*}{$\begin{array}{c}\text { Change in Disequilibriun } \\
\qquad \begin{array}{c}D_{O}=.1 \\
D_{E}=.1\end{array}\end{array}$} & $\begin{array}{l}.027^{\mathrm{b}} \\
.073\end{array}$ & $\begin{array}{c}-.023^{b} \\
.135\end{array}$ & $\begin{array}{l}.001^{\mathrm{b}} \\
.089\end{array}$ & $\begin{array}{r}-.002^{b} \\
.066^{b}\end{array}$ \\
\hline & \multicolumn{4}{|c|}{ Net Change in Probability of Search } \\
\hline \multirow[t]{2}{*}{$\begin{array}{c}\text { Change in Disequilibriur } \\
D_{O}=.1 \\
D_{E}=.1\end{array}$} & $\begin{array}{l}-.002^{b} \\
-.005\end{array}$ & $\begin{array}{l}-.003^{b} \\
-.003\end{array}$ & $\begin{array}{l}.001^{\mathrm{b}} \\
.018\end{array}$ & $\begin{array}{l}.001^{\mathrm{b}} \\
.021^{\mathrm{b}}\end{array}$ \\
\hline & \multicolumn{4}{|c|}{ Means } \\
\hline $\begin{array}{l}\text { Probability of move } \\
\text { Probability of search }\end{array}$ & $\begin{array}{l}.448 \\
.146\end{array}$ & $\begin{array}{l}.361 \\
.169\end{array}$ & $\begin{array}{l}.225 \\
.225\end{array}$ & $\begin{array}{l}.187 \\
.195\end{array}$ \\
\hline
\end{tabular}

a Probabilities estimated from models in Table 6B.

b Asymptotic $t$-test for coefficients in probit estimation not significantly different from zero at .05 level.

equilibrium housing demand increases the probability of moving by 7 to 13 percentage points. The effect on moving of an increase in initial disequilibrium is much smaller and is generally insignificant.

The net effect, however, of increases in disequilibrium upon searching behavior is rather small. A 10 percent increase in desired housing demand increases the probability of searching (but not moving) by 2 percent in Pittsburgh but has no net effect in Phoenix. It is important to note that searching is relatively "less successful" in Pittsburgh than in Phoenix. In Pittsburgh, only half of those households that consider moving (as evidenced by any search) actually move; in Phoenix roughly three-quarters move. The marginal success rate of searching, calculated from Table 7 for increased housing demand, goes up to over 75 percent in Pittsburgh and to 100 percent in Phoenix - suggesting that search is more intensive with larger disequilibrium.

If searching and moving are determined by the same factors, the estimation which recognizes both types of behavioral response will be more efficient since it includes additional information. However, if there are different determinants or if the determinants have differential weights in the two decisions, a specification error is introduced, and this may be more important than the efficiency gains. If the two types of behavior are generated by the same response function (with an intercept shift), the slope coefficients in the dichotomous and trichotomous probit models should be identical except for sampling error. In fact, the slope co- 
efficients, while similar, are consistently smaller in the trichotomous models as compared to the same dichotomous models, suggesting some behavioral difference in search and move responses. In general, the trichotomous choice models presented in Table 6, which incorporate more information about behavioral responses, are less satisfactory than the binary choice models in terms of goodness of fit and the precision of parameter estimates.

\section{CONCLUSIONS}

This paper estimates a model of intrametropolitan moving behavior based upon household disequilibrium in the demand for housing. Moving is viewed as the dynamic response to changes in household demands for residential housing. The precise specification of the model is motivated by two characteristics of the housing market-the high transactions costs of relocating and the limited possibilities of transforming housing configurations. These characteristics suggest that the actual consumption of residential housing at any point in time may deviate from desired levels of consumption (that level enjoyed in a frictionless world, given incomes, preferences, and relative prices). The model hypothesizes that the strength of the incentive to relocate varies with the gap between actual and equilibrium housing consumption.

The results provide rather strong support for this simple model of moving behavior-despite the fact that the models impose a rigid structure on moving behavior and that no allowance is made for the possibility that disequilibrium in specific components of the housing bundle (such as accessibility or space) may have differential effects on moving behavior.

The results clearly indicate the importance of changes in equilibrium demand in affecting moving decisions and search intensity. The strength of this finding is heightened by the consistency of results across time periods and across independent samples in two very different housing markets. The response of households to housing disequilibrium is roughly similar between housing markets, even though the character of the two markets is very different and even though the average moving propensity is almost twice as large in Phoenix as in Pittsburgh.

Finally, these results suggest caution in interpreting aggregate analyses of urban housing markets often pursued by economists. Standard urban models describe equilibrium in housing consumption and location based upon the distribution of income and other parameters of the urban economy such as employment location and transportation access. The models of individual housing decisions presented here suggest that significant levels of disequilibrium might exist among individual households at any point in time. Aggregation across individuals masks much of the disequilibrium (and the incentives for adjustment) by averaging across those individuals who are underconsuming and those who are overconsuming housing. If, as indicated above, both types of disequilibrium create moving incentives, the possibilities for changes in housing markets are larger than would be indicated by observing aggregate population characteristics. In order to ascertain the potential biases in aggregate analysis, it is necessary to extend this analysis to indicate the effects of moving on neigh- 
borhoods-both at origins and destinations. However, these models indicate the possibility of more rapid changes in urban areas than would be implied by aggregate analysis.

\section{APPENDIX}

\section{ESTIMATION OF EQUILIBRIUM HOUSING DEMANDS}

We assume that households who are observed to make active choices in the housing market and have overcome any inertia or transactions costs (i.e., recent movers) choose their utility maximizing or equilibrium levels of consumption. The equilibrium demand models reported in Table A-1 are estimated using the subsample of "recent mover" households in the HADE samples for each city, i.e., those who moved into their $t=0$ dwelling units within the past twelve months. ${ }^{20}$

Following previous research on housing demand (see, for example, Kain and Quigley [1975] or Straszheim [1975]), equilibrium demand is specified as a function of annual income, household size, age, years of education, race, and household assets-a crude proxy for wealth.

The dependent variable in each of the regressions is monthly rent, which differs from the index of monthly housing services (or gross rent) by the terms of individual landlord-tenant agreements. To adjust for variations in contractual terms, the demand equations also include dummy variables indicating whether or not the landlord provides major appliances.

The equilibrium demand equations were estimated in several alternative forms to investigate age or "life cycle" effects (see Hanushek and Quigley [1978] for details). The estimates presented in Table A-1 indicate a complete interaction of the age variable, i.e., stratification by households whose head is younger than 45 years and those whose head is older. ${ }^{21}$

The implications of these estimated demand equations are considered in more detail in another paper (Hanushek and Quigley [1978]). For present purposes, the demand equations are interpreted as characterizing the desired or equilibrium housing demand $\left(H_{t}^{d}\right)$ for each household, given individual household characteristics at each of three points in time $(t=0,1,2)$.

As with most demand studies based upon micro data, these demand estimates contain considerable error, as indicated by $R^{2}$ 's of approximately $.3 .^{22}$ As indicated in the text, it may be plausible to assume that the true equilibrium demand for a given household differs systematically from the models estimated because of unmeasured characteristics of households and their tastes. If these systematic differences are independent of the observed characteristics of households (as in a fixed individual difference error components model), the cross sectional estimates of the demand pa-

\footnotetext{
${ }^{20}$ For the demand estimation, which is carried out using the initial data on households, it is irrelevant which experimental group a household is ultimately assigned to. Therefore the demand estimation uses all sample households which satisfy the recent move condition, irrespective of subsequent experimental treatment.

21 Standard $F$-tests indicate that this specification is preferred to those including age in a linear or quadratic form.

22 Including the age stratification, the demand estimates reported in Table A-1 explain 38 percent of the variation in contract rents in Phoenix and 33 percent in Pittsburgh.
} 
TABLE A-1

HOUSING DEMAND EQUATIONS FOR RECENT MOVER HOUSEHOLDS STRATIFIED BY AGE

$H^{d}=g_{A}(y, A, 1)$

\begin{tabular}{|c|c|c|c|c|}
\hline \multirow[b]{2}{*}{ Variable } & \multicolumn{2}{|c|}{ Pittsburgh } & \multicolumn{2}{|c|}{ Phoenix } \\
\hline & Young & Old* & Young & Old $^{*}$ \\
\hline $\begin{array}{l}\text { Income } \\
\text { (thousands) }\end{array}$ & $\begin{array}{r}4.020 \\
(3.19)\end{array}$ & $\begin{array}{r}4.920 \\
(2.11)\end{array}$ & $\begin{array}{r}6.290 \\
(7.74)\end{array}$ & $\begin{array}{r}5.660 \\
(3.14)\end{array}$ \\
\hline $\begin{array}{l}\text { Assets } \\
\text { (thousands) }\end{array}$ & $\begin{array}{r}-1.310 \\
(0.98)\end{array}$ & $\begin{array}{l}1.118 \\
(1.58)\end{array}$ & $\begin{array}{l}1.230 \\
(0.93)\end{array}$ & $\begin{array}{r}1.230 \\
(1.32)\end{array}$ \\
\hline $\begin{array}{l}\text { Education } \\
\text { (years) }\end{array}$ & $\begin{array}{r}4.950 \\
(5.06)\end{array}$ & $\begin{array}{l}1.318 \\
(0.93)\end{array}$ & $\begin{array}{r}3.647 \\
(4.91)\end{array}$ & $\begin{array}{r}0.600 \\
(0.49)\end{array}$ \\
\hline Household Size & $\begin{array}{r}3.511 \\
(1.27)\end{array}$ & $\begin{array}{r}8.479 \\
(3.65)\end{array}$ & $\begin{array}{r}1.144 \\
(0.94)\end{array}$ & $\begin{array}{r}3.795 \\
(1.49)\end{array}$ \\
\hline Black & $\begin{array}{r}-15.383 \\
(3.61)\end{array}$ & $\begin{array}{r}-13.159 \\
(1.56)\end{array}$ & $\begin{array}{r}-25.541 \\
(4.02)\end{array}$ & $\begin{array}{r}-23.443 \\
(1.56)\end{array}$ \\
\hline $\begin{array}{l}\text { Other Nonwhite } \\
\text { (Spanish) }\end{array}$ & $\begin{array}{r}-14.935 \\
(0.80)\end{array}$ & $\begin{array}{r}-3.761 \\
(0.11)\end{array}$ & $\begin{array}{r}-16.370 \\
(4.20)\end{array}$ & $\begin{array}{r}-4.466 \\
(0.41)\end{array}$ \\
\hline Age & $\begin{array}{r}1.403 \\
(4.62)\end{array}$ & $\begin{array}{r}0.450 \\
(1.09)\end{array}$ & $\begin{array}{r}1.312 \\
(4.90)\end{array}$ & $\begin{array}{r}-0.586 \\
(1.47)\end{array}$ \\
\hline Refrigerator & $\begin{array}{r}22.267 \\
(2.89)\end{array}$ & $\begin{array}{r}-13.272 \\
(0.87)\end{array}$ & $\begin{array}{r}-6.470 \\
(1.40)\end{array}$ & $\begin{array}{r}2.295 \\
(0.23)\end{array}$ \\
\hline Stove & $\begin{array}{r}1.074 \\
(0.16)\end{array}$ & $\begin{array}{r}25.063 \\
(1.80)\end{array}$ & $\begin{array}{l}22.926 \\
(4.79)\end{array}$ & $\begin{array}{r}-6.868 \\
(0.57)\end{array}$ \\
\hline Air Conditioner & - & - & $\begin{array}{l}15.488 \\
(2.05)\end{array}$ & $\begin{array}{r}27.616 \\
(1.76)\end{array}$ \\
\hline Constant & 1.283 & 32.408 & 7.418 & 104.907 \\
\hline$R^{2}$ & 0.318 & 0.359 & .315 & .247 \\
\hline df & 313 & 91 & 502 & 128 \\
\hline
\end{tabular}

* Head of household aged 45 or more.

rameters will be unbiased even though the estimated equilibrium demand for a specific household will contain errors.

It is important to note the consideration of household expectations implied by this analysis. Some households which were observed to move during the twelve-month period may have done so on the basis of realized changes in demand or on the basis of expected demographic or economic changes. For example, births can be predicted with considerable accuracy before the actual event. To the extent that the expected changes occur within the twelve-month period of observation (i.e., before the actual baseline interview of HADE), no problems arise. However, if they do not occur and if the expectations are correlated with the observed household attributes, there will be some bias introduced in the equilibrium demand equations. The extent of possible bias depends upon the portion of expectations that are unrealized by the end of the observation period (when the economic and demographic data are gathered); biases from unrealized expectations cannot be ascertained from these data. 


\section{References}

Abt Associates. 1973. Evaluation Design of the Demand Experiment, processed.

Aitchison, J., and Silvey, S. D. 1957. "The Generalization of Probit Analysis to the Case of Multiple Responses." Biometrika 44 (June): 131-40.

Alonso, William. 1964. Location and Land Use. Cambridge, Mass.: Harvard University Press. de Leew, Frank, and Ekanem, Nkanta. 1971. "The Supply of Rental Housing." American Economic Review 61 (Dec.): 806-17.

Hanushek, Eric A., and Jackson, John E. 1977. Statistical Methods for Social Scientists. New York: Academic Press.

Hanushek, Eric A., and Quigley, John M. 1978. "The Dynamics of the Housing Market: A Stock Adjustment Model of Housing Consumption." Journal of Urban Economics 5 (Oct.).

Kain, John F., and Quigley, John M. 1975. Housing Markets and Racial Discrimination: A Micro Economic Analysis. New York: National Bureau of Economic Research.
[Merrill, Sally, principal author], Abt Associates. 1976. Housing Expenditures and Quality. Part III, processed.

Muth, Richard F. 1969. Cities and Housing. Chicago: University of Chicago Press.

Quigley, John M., and Weinberg, Daniel H. 1977. "Intra-Metropolitan Residential Mobility: Review and Synthesis." International Regional Science Review 2 (Fall): 41-66.

Rothschild, Michael. 1974. "Searching for the Lowest Price when the Distribution of Prices is Unknown." Journal of Political Economy 82 (July/Aug.): 689-712.

Schafer, Robert. Forthcoming. "Racial Discrimination in the Boston Housing Market." Journal of Urban Economics.

Shelton, John P. 1968. "The Cost of Renting versus Owning a Home." Land Economics 44 (Feb.): 49-72.

Straszheim, Mahlon. 1975. An Econometric Analysis of the Housing Market. New York: National Bureau of Economic Research.

U.S. Department of Commerce, Bureau of the Census, and U.S. Department of Housing and Urban Development. 1975. Annual Housing Survey: 1973, Part D. 